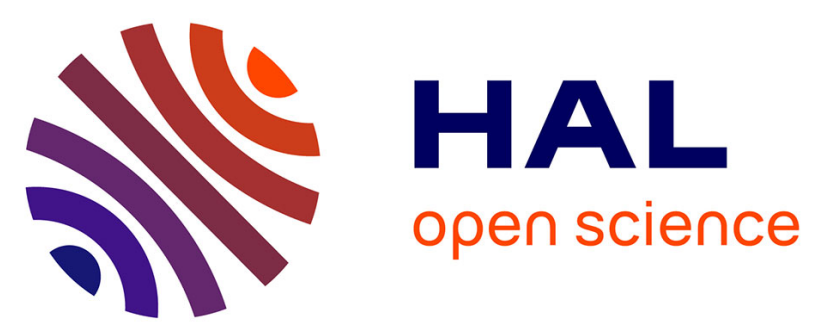

\title{
Working conditions and psychotropic drug use: cross-sectional and prospective results from the french national SIP study
}

Marion Lassalle, Jean-François Chastang, Isabelle Niedhammer

\section{To cite this version:}

Marion Lassalle, Jean-François Chastang, Isabelle Niedhammer. Working conditions and psychotropic drug use: cross-sectional and prospective results from the french national SIP study. Journal of Psychiatric Research, 2015, 63, pp.50-57. 10.1016/j.jpsychires.2015.02.019 hal-01130279

\section{HAL Id: hal-01130279 \\ https://hal.sorbonne-universite.fr/hal-01130279}

Submitted on 11 Mar 2015

HAL is a multi-disciplinary open access archive for the deposit and dissemination of scientific research documents, whether they are published or not. The documents may come from teaching and research institutions in France or abroad, or from public or private research centers.
L'archive ouverte pluridisciplinaire HAL, est destinée au dépôt et à la diffusion de documents scientifiques de niveau recherche, publiés ou non, émanant des établissements d'enseignement et de recherche français ou étrangers, des laboratoires publics ou privés. 
Working conditions and psychotropic drug use: cross-sectional and prospective results from the French national SIP study

Marion Lassalle ${ }^{\text {a,b }}$, Jean-François Chastang ${ }^{a, b}$, Isabelle Niedhammer ${ }^{\text {a,b }}$

${ }^{a}$ INSERM, UMR_S 1136, Pierre Louis Institute of Epidemiology and Public Health, Department of social epidemiology, F-75013, Paris, France

${ }^{\mathrm{b}}$ Sorbonne Universités, UPMC Univ Paris 06, UMR_S 1136, Pierre Louis Institute of Epidemiology and Public Health, Department of social epidemiology, F-75013, Paris, France

\section{Correspondence to:}

Dr. Isabelle Niedhammer

INSERM UMRS 1136 - IPLESP

Team 7 (ERES)

Faculté de Médecine Pierre et Marie Curie - pôle Saint-Antoine

27 rue de Chaligny

F-75012 Paris

France

Email: isabelle.niedhammer@inserm.fr

Short running head: Working conditions and psychotropic drug use

Word count of abstract: 218

Word count: 4437

2 appendices

53 references

4 Tables 


\begin{abstract}
Prospective studies exploring the associations between a large range of occupational factors and psychotropic drug use among national samples of workers are seldom. This study investigates the cross-sectional and prospective associations between occupational factors, including a large set of psychosocial work factors, and psychotropic drug use in the national French working population. The study sample comprised 7542 workers for the cross-sectional analysis and 4213 workers followed up for a 4-year period for the prospective analysis. Psychotropic drug use was measured within the last 12 months and defined by the use of antidepressants, anxiolytics or hypnotics. Three groups of occupational factors were explored: classical and emergent psychosocial work factors, working time/hours and physical work exposures. Weighted Poisson regression analyses were performed to adjust for covariates. In the cross-sectional analysis, psychological demands, low social support and hiding emotions were associated with psychotropic drug use. Job insecurity for men and night work for women were associated with psychotropic drug use. In the prospective analysis, hiding emotions and physical exposure were predictive of psychotropic drug use. Dose-response associations were observed for the frequency/intensity of exposure and repeated exposure to occupational factors. This study underlines the role of psychosocial work factors, including emergent factors, in psychotropic drug use. Prevention policies oriented toward psychosocial work factors comprehensively may be useful to reduce this use.
\end{abstract}

Keywords: psychosocial work factors; occupational factors; working conditions; psychotropic drug use 


\section{Introduction}

Psychotropic drugs are used to treat mental illness, such as anxiety, depression or sleep disorders. Within the last decades, the consumption has increased in Western countries. In Europe, the highest 12-month prevalence of psychotropic drug consumption was observed for France $(19.2 \%)$. This prevalence was $15.5 \%$ in Spain and $13.7 \%$ in Italy (Alonso et al., 2004). In the US, the 1-month prevalence was $11.1 \%$ (Paulose-Ram et al., 2007). Psychotropic drugs may cause adverse reactions and their widespread use involves health consequences and costs. In particular, at the workplace, psychotropic drug use may reduce performance and cause accident (Palmer et al., 2014). Thus, reducing psychotropic drug consumption has become a public health objective and improving knowledge on risk factors has become essential. Classical risk factors of psychotropic consumption include female gender (Alonso et al., 2004), older age (Alonso et al., 2004), low socioeconomic status (Hansen et al., 2004), living alone (Metsa-Simola \& Martikainen, 2013) and stressful life events (Blanc \& Marchand, 2010;Bourbonnais et al., 1996). In addition, it has been shown that working conditions play a role in psychotropic drug use.

The association between occupational factors and psychotropic drug use has been explored in several studies. Three groups of working conditions were considered: psychosocial work environment, working hours/time and physical environment. Psychosocial work conditions include classical factors, described by the job strain (Karasek et al., 1998) and effort-reward imbalance models (Siegrist, 1996). Karasek's model integrates three dimensions: psychological demands, decision latitude and social support. The combination of high psychological demands and low decision latitude generates job strain and iso-strain when associated with low social support. All these factors may cause deleterious health effects, in particular on mental health. Studies reported associations between Karasek's factors, especially psychological demands, low social support and/or job strain, and psychotropic drug use (Bonde et al., 2009;D'errico et al., 2011;Lavigne \& Bourbonnais, 2010;Moisan et al., 1999;Pelfrene et al., 2002;Pelfrene et al., 2004;Sinokki et al., 2009;Sinokki et al., 2010;Storr et al., 1999; Thielen et al., 2011;Virtanen et al., 2007). More recently, new psychosocial work factors were described as consequences of changes in labour market conditions. Some studies showed that workplace violence/bullying (Lallukka et al., 2012;Lavigne \& Bourbonnais, 2010;Madsen et al., 2011;Niedhammer et al., 2011;Traweger et al., 2004; Vartia, 2001) increased the risk of psychotropic drug use. However, some psychosocial work factors have 
not yet been sufficiently studied, such as the factors related to emotional demands (Madsen et al., 2010;Madsen et al., 2014;Magnusson Hanson et al., 2013), effort-reward imbalance model (Godin et al., 2005;Lavigne \& Bourbonnais, 2010), job insecurity (Rugulies et al., 2010b) or work-life imbalance (Lallukka et al., 2013;Magnusson Hanson et al., 2014;Nylen et al., 2007). Other factors have been neglected in the literature like role stressors or tensions with the public. Factors related to working time/hours may also increase the risk of psychotropic drug use. Authors showed associations with shift and night work (D'errico et al., 2011;Niedhammer et al., 1995), but the role of other factors, such as unpredictable working hours or long working hours have little been explored in the literature and their role remains unclear (Blanc \& Marchand, 2010;D'errico et al., 2011;Laaksonen et al., 2012;Marchand \& Blanc, 2010; Verger et al., 2004). Few studies examined physical working conditions in association with psychotropic drugs. An association between chemical exposure and psychotropic drug use was found in a very specific sample of workers (Attia et al., 2006).

The objectives of this study were to examine the associations between occupational factors and psychotropic drug use in the French working population. Its innovative aspects included the study of a national sample of workers, a large set of psychosocial work factors and other occupational factors, cross-sectional and prospective data, and classical risk factors of psychotropic drug use as covariates.

\section{Methods}

\section{Study sample}

The study was based on the data of the national SIP survey (Santé et Itinéraire Professionnel), carried out by the French Ministries of Labour (DARES) and Health (DREES), the French Center for Employement Studies (CEE) and the French National Institute for Statistics and Economic Studies (INSEE). In 2006, households were randomly selected from the 1999 census, that was updated for new housings, and one individual aged between 20 and 74 years was randomly selected to be interviewed in each household. Finally, 13648 men and women from the French general population were interviewed by a trained interviewer at respondent's home. The response rate was $76 \%$. Four years later, in 2010, they were contacted again for the second wave of the survey, and 11016 individuals participated (i.e. a follow-up rate of 81\%). The present study was restricted to people who were working. Among the total sample of 13648 people of the general population interviewed in 2006, 7542 subjects were working and 
included in the cross-sectional analysis. Among them, in 2010, 1288 were lost to follow-up, 1175 were psychotropic drug users in 2006, and 866 were not working any longer in 2010, leading to a sample size of 4213 for the prospective analysis. Four previous studies by our team have already been published on other topics using these data (Malard et al., 2014;Murcia et al., 2013;Murcia et al., 2015;Niedhammer \& Chastang, 2014). The SIP survey was approved by the French Ethics Committees (CNIL and CNIS).

\section{Psychotropic drug use}

Psychotropic drug intake was recorded separately for anxiolytics, antidepressants and hypnotics. Three lists of brand and generic name products (Appendix 1), covering all the drugs present on the market at the time of the survey, including both prescription and nonprescription drugs, were presented to the participants. Subjects were asked whether they used such drugs within the last twelve months in 2006 and 2010. In the study, psychotropic drug consumption was defined by the use of antidepressants, regardless of frequency, or the use of anxiolytics or hypnotics at least once per week.

\section{Occupational factors (Appendix 2)}

Occupational factors were measured in 2006 and 2010. Psychosocial work conditions included classical factors: psychological demands, decision latitude and social support from colleagues. These three factors were used as proxies of the dimensions of Karasek's model. Reward was used as a proxy for the effort-reward imbalance model dimension. Emerging psychosocial working conditions were also studied: hiding emotions, role conflict, ethical conflict, tensions with the public, job insecurity and work-life imbalance. Four variables were used to measure working time/hours: long working hours, night work, shift work and unpredictable working hours. Physical working conditions included biomechanical exposure, physical exposure and chemical exposure.

All the items related to occupational factors were coded using 4 response categories (never/rarely/often/always). Variables or scores were dichotomised at the median of the distribution of the total sample. Four groups of exposure to occupational factors were also constructed to define repeated exposure: exposed in neither 2006 nor 2010, exposed in 2006 and non-exposed in 2010, non-exposed in 2006 and exposed in 2010, and exposed in both 2006 and 2010. Consequently, three measures of exposure were used: binary variable, frequency variable, and repeated exposure variable. 


\section{Covariates}

The following classical risk factors of psychotropic drug use, measured in 2006, were considered: age, occupational groups (using the French classification of occupations), marital status, dependent child under 3 years old, social support outside work (4 items: having someone to rely on to discuss personal issues or take a difficult decision-besides partner-, having someone to help on daily tasks, like do-it-yourself or child care, or to borrow some objects, and for each of these two items, need more help than help received), life events before 18 years old (12 items: disability, long illness, serious health problems or death of close family member, etc.), and life events between 2002 and 2006 (4 items: separation, death or care of close family member, strong deterioration in living conditions).

\section{Statistical methods}

To be representative of the French working population of 2006, weights were calculated using marginal calibration and inverse probability weighting to control for the potential biases due to non-response in 2006 and attrition in 2010 (De Riccardis, 2012). A marginal calibration on age, work status (working/unemployed/non-working)×age, urban area, size of household, occupation and economic activity was performed on the sample in 2006. Homogeneous response groups were formed based on characteristics in 2006 (work status, urban area, age, level of education, gender and self-reported health), and the probability of being interviewed in 2010 was calculated for each group. Weights calculated by marginal calibration (for nonresponse in 2006) were multiplied by the inverse probability of being interviewed in 2010 . Finally, a second marginal calibration on territorial unit, urban area, agexgender, education, nationality, and size of household was performed on the sample of individuals interviewed in 2006 and 2010 to be representative of the population of 2006 . Weights were included in all statistical analyses.

The description of the sample was performed for men and women separately. Rao-Scott Chisquare tests were used to compare men and women for all studied variables in 2006 . Weighted Poisson regression analyses were performed to study the associations between occupational factors and psychotropic drug use and to adjust for covariates among the total sample of men and women. Psychotropic drug use was the outcome. Firstly, each occupational factor was introduced separately in the models. Secondly, all occupational factors were introduced simultaneously in final models. Although occupational factors 
displayed interrelations, no collinearity was detected in these models. In the final models using binary variables of exposure, interaction tests were performed between high psychological demands and low decision latitude, to test the job strain hypothesis. However, none interaction was found between high psychological demands and low decision latitude. Interaction terms were also introduced one by one between gender and each occupational factor to examine potential differences in the associations between genders. Two types of analyses were conducted. In the cross-sectional analysis, occupational factors, covariates and psychotropic drug use were all measured in 2006. The prospective analysis aimed at exploring the associations between occupational factors and covariates measured in 2006 and psychotropic drug consumption in 2010 among the sub-sample of those who were non-users in 2006.

Dose-response associations were explored for the occupational factors that displayed significant associations with psychotropic drug consumption in the final models. We introduced these factors simultaneously in weighted Poisson regression models (including covariates) using the variables with the initial coding in 4 frequency categories (never/rarely/often/always) in order to determinate trend p-values. We also repeated the analyses taking repeated exposures into account.

Sensitivity analyses were performed to check the robustness of the results. The following additional covariates were added in the models: health status (longstanding disease, disability, after-effect of accident), alcohol/tobacco consumption, work/job (economic activity of the company, public/private sector, employee/self-employed status) and personality (overcommitment at work). In the prospective analysis, information about job change and unemployment/inactivity periods between the two data collections in 2006 and 2010 was also included in the models.

All the analyses were carried out using SAS and STATA softwares.

\section{Results}

\section{Cross-sectional analysis}

The description of the sample in 2006 is presented in Table 1. Almost a quarter of women used psychotropic drugs. This 12-month prevalence was twice the prevalence for men. 
Anxiolytics represent the most common used therapeutic class for both genders. The use of more than one psychotropic drug (of different therapeutic classes) was frequently observed: among psychotropic drug users, $36.10 \%$ of women and $36.26 \%$ of men used 2 or more psychotropic drugs (weighted data). Men were more likely to be managers/professionals and manual workers, and women were more likely to be clerks/service workers. The prevalence of dependent child was higher for men than for women. Women were more likely to live alone, to have low social support outside work, and to experience stressful life events. Men were more likely to be exposed to high psychological demands, low social support, ethical conflicts and job insecurity. Women had a higher prevalence of exposure to hiding emotions and tensions with the public. Men were more likely to be exposed to all other occupational factors related to working time/hours and physical work environment.

Table 2 presents the cross-sectional associations between occupational factors and psychotropic drug consumption in 2006 after adjustment for covariates. When introduced separately in the models, all psychosocial work factors except work-life imbalance were associated with psychotropic drug use. Long working hours were found to be a protective factor for this use, and biomechanical exposure a risk factor. After adjustment for all occupational factors, associations were observed for psychological demands, low social support, hiding emotions and job insecurity with psychotropic drug use. A negative association between long working hours and psychotropic drugs was observed. No association was found for any physical working conditions. Two interactions were observed regarding gender showing that job insecurity for men $(\mathrm{RR}=1.38,95 \% \mathrm{CI}: 1.12 ; 1.69)$ and night work for women $(\mathrm{RR}=1.22,95 \% \mathrm{CI}: 1.01 ; 1.55)$ were associated with psychotropic drug use but not for the other gender.

Dose-response associations between the frequency/intensity of exposure to occupational factors and psychotropic drug consumption in 2006 were studied using the initial coding (frequency) or quartiles (not showed). Significant positive trends were observed for psychological demands, low social support, hiding emotions and job insecurity with psychotropic drugs, and a negative trend between long working hours and psychotropic drugs.

\section{Prospective analysis}

Table 3 presents the prospective associations between occupational factors in 2006 and psychotropic drug consumption in 2010 after adjustment for covariates. Psychological 
demands, low decision latitude, hiding emotions and physical exposure predicted psychotropic drug use when the occupational factors were introduced separately. After adjustment for all occupational factors, hiding emotions and physical exposure remained predictive factors of use.

A positive trend was observed between the frequency/intensity of exposure to hiding emotions and psychotropic drugs and a negative trend between the frequency/intensity of exposure to long working hours and psychotropic drugs.

Table 4 presents the results for the repeated measures of exposure in association with psychotropic drug use in 2010. Past exposure (exposure in 2006 only) was not significantly associated with psychotropic drugs, one exception being hiding emotions. The effect of repeated exposures, i.e. in both 2006 and 2010, was stronger than recent exposures (in 2010 only). The results were stable in the two analyses exploring each factor separately and all factors simultaneously for high psychological demands, low decision latitude and hiding emotions.

\section{Discussion}

\section{Main results}

In the cross-sectional analysis, when the occupational factors were studied simultaneously, psychological demands, low social support, hiding emotions and job insecurity were associated with psychotropic drug use. Two factors were found to be risk factors for one gender only: job insecurity for men and night work for women. In the prospective analysis, hiding emotions and physical exposure were predictive of psychotropic drug use. When each occupational factor was studied separately (a less conservative approach), a higher number of factors were found to be associated with psychotropic drug use. Dose-response associations were observed for both the frequency/intensity of exposure and repeated exposure to occupational factors.

\section{Comparison with literature}

The prevalence of psychotropic drug use reached almost $25 \%$ among women and was twice the prevalence among men. The high prevalence of use observed in our study is consistent with other studies showing that France has a particularly high prevalence of use of these drugs 
compared to other countries (Alonso et al., 2004; Inserm, 2012). The gender difference is consistent with the literature and most studies founded a sex ratio of about 2 (Alonso et al., 2004). Gender differences were also observed for the prevalence of exposure to occupational factors.

Few previous studies investigated psychosocial work factors, working hours/time and physical working conditions simultaneously in association with psychotropic drug use. In our study, psychosocial work factors were found to be associated with psychotropic drug use, the associations being more seldom for the other occupational factors related to working time/hours and physical work environment.

The comparison with the literature was performed on the basis of the results provided by the models including all occupational factors together. Regarding the dimensions of the job strain model, psychological demands and low social support were found to be associated with psychotropic drug use in the cross-sectional analysis. Previous studies reported that psychological demands (D'errico et al., 2011;Pelfrene et al., 2002;Pelfrene et al., 2004; Thielen et al., 2011; Virtanen et al., 2007) and/or low social support (Bonde et al., 2009;Lavigne \& Bourbonnais, 2010;Pelfrene et al., 2002;Sinokki et al., 2009;Sinokki et al., 2010; Thielen et al., 2011) were risk factors of psychotropic drug use. Around half of these studies had a prospective design.

Hiding emotions that may be considered as a dimension of emotional demands were associated with psychotropic drug use in both cross-sectional and prospective analyses in our study. This stable result is in agreement with some previous prospective studies (Madsen et al., 2010;Madsen et al., 2014;Magnusson Hanson et al., 2013). Among these three studies only one explored demands for hiding emotions specifically (Madsen et al., 2010). However, one prospective study did not report an association between emotional demands and the use of antidepressant medicine (Thielen et al., 2011).

Low reward was not associated with psychotropic drug use in our study. Only a few rare studies explored the dimensions of effort-reward imbalance model, and the authors found significant associations for low reward (Lavigne \& Bourbonnais, 2010) and/or effort-reward imbalance (Godin et al., 2005;Lavigne \& Bourbonnais, 2010). 
Two role stressors were studied in our study, role and ethical conflicts, and both were not associated with psychotropic drug use. We found one previous study only exploring role stressors and this study reported significant associations between conflicting demands and antidepressant use (Magnusson Hanson et al., 2013).

Tensions with the public were not associated with psychotropic drug use in our study. A study by Madsen et al. (Madsen et al., 2010) showed that the use of antidepressants was increased for healthcare workers (a group of employees working with people) but this increased risk was attenuated when adjusted for emotional demands.

Job insecurity was associated with psychotropic drugs among men in the cross-sectional analysis. Three previous studies reported findings about job insecurity or markers that may be related to job insecurity. Job insecurity predicted incident use of antidepressants among Danish employees with a history of prolonged unemployment (Rugulies et al., 2010b). Organisational downsizing, that may increase job insecurity, was a predictive factor of psychotropic drug use in a prospective study of municipal employees in Finland (Kivimaki et al., 2007). Temporary employment, that may involve job insecurity, was associated with antidepressant use and antidepressant use increased as the stability of the temporary job contract decreased in a prospective study of employees in 10 Finnish municipalities (Virtanen et al., 2008).

Work-life imbalance was not associated with psychotropic drugs in our study. Three studies (including two prospective studies) reported that work-life imbalance or conflicts were risk factors of psychotropic drug use (Lallukka et al., 2013;Magnusson Hanson et al., 2014;Nylen et al., 2007).

The protective effect of long working hours, found in our cross-sectional analyses, is consistent with the literature (Blanc \& Marchand, 2010; Marchand \& Blanc, 2010; Verger et al., 2004) and may be explained by a potential healthy worker effect. However, another study reported an association between overtime and the use of sleeping pills (Laaksonen et al., 2012). No association with unpredictable working hours was found in our analyses. A previous study, that used a wider definition of unpredictable working hours (including shift work and on-call work), found no association with psychotropic drug use (Blanc \& Marchand, 
2010). Another study also found no association between irregular working hours and psychotropic drug use (Marchand \& Blanc, 2010).

We found an association between physical exposure at work and psychotropic drugs in our prospective analysis. Previous studies found non-significant associations between physical exposures and psychotropic drugs (Blanc \& Marchand, 2010;D'errico et al., 2011;JacquinetSalord et al., 1993;Laaksonen et al., 2012;Marchand \& Blanc, 2010;Pelfrene et al., 2002; Thielen et al., 2011).

Dose-response associations were observed between occupational factors and psychotropic drug use in terms of frequency/intensity of exposure and/or repeated exposure combining the two measures of exposures in 2006 and 2010. These results suggest that for some factors, especially psychosocial work factors, such as psychological demands, decision latitude, social support, emotional demands and job insecurity, the use of psychotropic drugs may increase with the frequency/intensity of exposure and/or repeated exposure to these factors. Few studies explored dose-response associations. A previous study reported that the more frequent and the longer the exposure to workplace bullying, the stronger the association with psychotropic drug use (Niedhammer et al., 2011).

\section{Strengths and limitations}

The strengths of the study deserve to be mentioned. The study was based on a large national sample of the French working population, i.e. not a specific or selected population of workers, with satisfactory response and follow-up rates. All analyses included weights to control for potential non-response and attrition biases and provided representative results that may be extrapolated to the whole population. Gender differences were observed in the prevalence of psychotropic drug use and of occupational factors. In addition, gender differences were also tested in the associations between occupational factors and psychotropic drug use, but only a few interactions were found to be significant, suggesting that there may be only small differences between genders in the impact of these factors on use (Niedhammer et al., 2000). The study covered a large range of occupational factors including psychosocial work factors, working time/hours and physical work environment. The associations were mainly observed for psychosocial work factors. Among the psychosocial work factors considered, our study included both classical and emergent factors. Psychotropic drug consumption was used as an objective assessment of mental disorders as in France these medications are generally 
prescribed by physicians on the basis on a clinical diagnosis. Exhaustive lists of drug names were presented to the people, something that may reduce recall and reporting bias. Because psychotropic medication may be negatively perceived, the questions and lists did not mention medical indications or therapeutic classes (psychotropic drugs, antidepressants, anxiolytics or hypnotics). Both cross-sectional and prospective analyses were conducted and provided complementary findings. The cross-sectional analysis gave estimates for the prevalence of psychotropic drug use and of exposure to occupational factors. This analysis may provide information about short-term effects of occupational factors on psychotropic drug use. Indeed, adjustment disorders may occur within 3 months after the start of a stressful event and may disappear within 6 months after its stop (American Psychiatric Association, 2013). In the prospective analysis, the assessment of occupational factors preceded psychotropic drug use, consequently the temporal sequence may be in favour of causal associations. Two types of models were built. Occupational factors were first introduced separately, then all together in Poisson regression models. As there may be complex interrelations between occupational factors (factors may be causes or consequences of others), authors argued that taking all occupational factors into account may lead to overadjustment and reduce the strength of the associations (Rugulies et al., 2010a). Thus, fully-adjusted models may be seen as a conservative approach. Only few studies explored dose-response associations between occupational factors and psychotropic drug use. We found that there may be dose-response associations in terms of frequency and duration of exposure, something that has been rarely demonstrated before and that may reinforce the plausibility of the associations observed. Well-known risk factors of psychotropic drug use were included as covariates and the results were consistent with the literature. Sensitivity analyses were performed to check the robustness of the results and displayed similar results.

The limitations of the study may be the following. As the study was based on a sample of workers, a healthy worker effect may have occurred and led to an underestimation of the associations between occupational factors and psychotropic drug use, or even to negative associations, such as those observed for long working hours. Classical psychosocial work factors were not assessed using validated questionnaires. This may lead to imprecision in the variables measured. However, other authors underlined the interest and validity of constructing proxies (Karasek et al., 2007). In addition, as most of our measures for psychosocial work factors were based on one item only, we were not able to evaluate the internal consistency of these measures. Some psychosocial work factors may have been 
neglected as they were not available in the SIP survey such as workplace violence and bullying (Lallukka et al., 2012;Lavigne \& Bourbonnais, 2010;Madsen et al., 2011;Niedhammer et al., 2011;Traweger et al., 2004). Psychotropic drug use may be an imperfect measure of mental health. Authors suggested that, according to the 'rule of halves', only half of patients suffering from mental disorders may be diagnosed, only a half of those diagnosed may be treated, and only a half of them may take the prescribed treatment effectively (Wittchen et al., 2003). In addition, in the prospective analysis, no information was available on psychotropic drug use between the two data collections. The study of the three therapeutic classes (antidepressants, anxiolytics and hypnotics) separately may suffer from a lack of statistical power because of the frequent use of two drugs or more simultaneously (especially anxiolytics combined with another psychotropic drug), that concerned more than one third of the sample. Furthermore, the results for anxiolytics were similar to the results for all psychotropic drugs, which may be expected given that anxiolytics are the most used type of psychotropics (2/3 of the people using psychotropics were taking anxiolytics). In the final models of the cross-sectional analyses, low decision latitude, hiding emotions and job insecurity were associated with antidepressants, and psychological demands and hiding emotions with hypnotics. For the prospective analyses, hiding emotions predicted antidepressant use and physical exposure predicted hypnotic use. Opioid analgesics were not included in our study and no information was collected about abuse and misuse of psychotropic drugs. A reverse causation may be suspected in the cross-sectional analysis, and there may be a lack of statistical power in the prospective analysis, compared to the crosssectional analysis, because of attrition and withdrawals from the labour market (mainly because of retirement). Both occupational factors and psychotropic drug use were assessed using self-report. Thus, a reporting bias may lead to overestimate the associations observed, and this bias may be stronger in the cross-sectional analysis as both exposures and outcome were collected at the same time. This reporting bias might affect some psychosocial work factors more than others. Indeed, cognitive and emotional processing depends on the wording of the items and might be high for some of our items of psychosocial work factors (Frese \& Zapf, 1988). In particular, this might explain the results for hiding emotions, that were systematically significant in all the analyses in our study.

\section{Conclusion}

The present study underlined the role of psychosocial work factors in psychotropic drug use, and showed associations between emergent factors, poorly documented to date, and this use. 
Prevention policies oriented towards psychosocial work factors may be useful for mental health. More research may be needed to confirm our results and improve our knowledge on the mechanisms leading to psychotropic drug consumption.

Acknowledgements: The authors thank the members of the DARES, DREES, CEE and INSEE, and all the people who participated to the SIP survey and made this study possible. This study was founded by the French ministry of labour (DARES, grant no 2200727156). 
Appendix 1

Lists of brand and generic name products

\begin{tabular}{|c|c|c|c|c|}
\hline Antidepressants & & Hypnotics & Anxiolytics & \\
\hline List 1 & List 2 & List 3 & List 4 & List 5 \\
\hline Agomélatine & Arkogélules & Arkogélules & Alprazolam & Anxietum \\
\hline Anafranil & millepertuis & valériane & Atarax & Covatine \\
\hline Athymil & Cymbalta & Calcibronat & Bromazepam & Euphytose \\
\hline Citalopram & Defanyl & Circadin & Buspar & Lorazepam \\
\hline Clomipramine & Divarius & Donormyl & Buspirone & Quietude \\
\hline Deroxat & Elavil & Galirène & Diazepam & Veratran \\
\hline Effexor & Ludiomil & Halcion & Equanil & Victan \\
\hline Floxyfral & Marsilid & Havlane & Lexomil & Prazépam \\
\hline Fluoxetine & Mianserine & Imovane & Lysanxia & \\
\hline Fluvoxamine & Mildac & Mepronizine & Meprobamate & \\
\hline Ixel & Moclamine & Mogadon & Nordaz & \\
\hline Laroxyl & Procalmil & Noctamide & Quiétiline & \\
\hline Mirtazapine & Prosoft & Noctran & Seresta & \\
\hline Norset & Prothiaden & Nopron & Stresam & \\
\hline Paroxétine & Quitaxon & Normison & Temesta & \\
\hline Prozac & Seroplex & Nuctalon & Tranxène & \\
\hline Seropram & Sertraline & Passinevryl & Urbanyl & \\
\hline Stablon & Surmontil & Rohypnol & Valium & \\
\hline Valdoxan & Tofranil & Sedalozia & Xanax & \\
\hline $\begin{array}{c}\text { Venlafaxine } \\
\text { Zoloft }\end{array}$ & Trazolan & $\begin{array}{l}\text { Sedatif Tiber } \\
\text { Spasmine } \\
\text { Stilnox } \\
\text { Théralène } \\
\text { Tranquital } \\
\text { Zolpidem } \\
\text { Zopiclone }\end{array}$ & & \\
\hline
\end{tabular}


Appendix 2

List of the items for occupational factors

\section{Psychosocial work factors:}

- psychological demands (3 items): work under pressure, too many things to do, excessive amount of work

- decision latitude (2 items): freedom to decide how to do the work, use of skills

- $\quad$ social support from colleagues (1 item): good relationships with colleagues

- reward (1 item): fair feedback on the work done

- hiding emotions (1 item): hiding feelings at work or having to pretend to be in good $\operatorname{mood}$

- role conflict ( 1 item): not being able to work following best practices

- ethical conflict (1 item): exposure to unethical situations

- tensions with the public (1 item): exposure to stressful situations with users, students, patients, customers

- job insecurity (1 item): fear of job loss

- $\quad$ work-life imbalance (1 item): work in line with family life

\section{Working time/hours variables:}

- long working hours (1 item): more than 48 hours per week

- night work (1 item): working hours between midnight and 5am

- $\quad$ shift work (1 item): rotating shifts

- unpredictable working hours (1 item): irregular and unpredictable working hours

\section{Physical work factors:}

- biomechanical exposure (3 items): manual material handling, long standing/crouching/bending/arms above the shoulders/force position, exposure to machine/tool vibrations

- physical exposure (2 items): unable to hear someone who is 2 or $3 \mathrm{~m}$ away, even if the person shouts, exposure to heat, cold, humidity or dirtiness

- chemical exposure (1 item): exposure to dust, fume, chemical products or germs 


\section{References}

Alonso J, Angermeyer MC, Bernert S, Bruffaerts R, Brugha TS, Bryson H, de GG, Graaf R, Demyttenaere K, Gasquet I, Haro JM, Katz SJ, Kessler RC, Kovess V, Lepine JP, Ormel J, Polidori G, Russo LJ, Vilagut G, Almansa J, rbabzadeh-Bouchez S, Autonell J, Bernal M, Buist-Bouwman MA, Codony M, Domingo-Salvany A, Ferrer M, Joo SS, Martinez-Alonso M, Matschinger H, Mazzi F, Morgan Z, Morosini P, Palacin C, Romera B, Taub N, Vollebergh WA. Psychotropic drug utilization in Europe: results from the European Study of the Epidemiology of Mental Disorders (ESEMeD) project. Acta Psychiatr.Scand Suppl 2004; 420:55-64.

American Psychiatric Association. Diagnostic and Statistical Manual of Mental Disorders (5th ed.). Arlington, VA: American Psychiatric Publishing 2013.

Attia JR, D'Este C, Schofield PW, Brown AM, Gibson R, Tavener M, Horsley K, Harrex W, Ross J. Mental health in F-111 maintenance workers: the study of Health Outcomes in Aircraft Maintenance Personnel (SHOAMP) general health and medical study. J.Occup.Environ.Med 2006; 48:682-691.

Blanc ME, Marchand A. [The contribution of work and other social determinants to the onset of psychotropic drug use among workers in Canada]. Can.J.Public Health 2010; 101 Suppl 1:S63-S68.

Bonde JP, Munch-Hansen T, Wieclaw J, Westergaard-Nielsen N, Agerbo E. Psychosocial work environment and antidepressant medication: a prospective cohort study. BMC.Public Health 2009; 9:262.

Bourbonnais R, Brisson C, Moisan J, Vezina M. Job strain and psychological distress in white-collar workers. Scand.J.Work Environ.Health 1996; 22:139-145.

D'errico A, Cardano M, Landriscina T, Marinacci C, Pasian S, Petrelli A, Costa G. Workplace stress and prescription of antidepressant medications: a prospective study on a sample of Italian workers. Int.Arch.Occup.Environ.Health 2011; 84:413-424.

De Riccardis N. Traitements de la non-réponse et calages pour l'enquête santé et itinéraire professionnel de 2010. Direction de la recherche, des études, de l'évaluation et des statistiques - DREES, Document de Travail - Série Sources et Méthodes 36 (Septembre), 2012.

Frese M, Zapf D. Methodological issues in the study of work stress: Objective vs subjective measurement of work stress and the question of longitudinal studies. In: Cooper CL, Payne R, editors. Causes, coping and consequences of stress at work. Chichester, England: Wiley series on studies in occupational stress, John Wiley \& Sons Ltd, 1988. p. 375-411.

Godin I, Kittel F, Coppieters Y, Siegrist J. A prospective study of cumulative job stress in relation to mental health. BMC.Public Health 2005; 5:67.

Hansen DG, Sondergaard J, Vach W, Gram LF, Rosholm JU, Mortensen PB, Kragstrup J. Socio-economic inequalities in first-time use of antidepressants: a population-based study. Eur.J.Clin.Pharmacol. 2004; 60:51-55.

Inserm. Médicaments psychotropes : Consommations et pharmacodépendances. Paris: Les Editions Inserm, Collection Expertise Collective, 2012.

Jacquinet-Salord MC, Lang T, Fouriaud C, Nicoulet I, Bingham A. Sleeping tablet consumption, self reported quality of sleep, and working conditions. Group of Occupational Physicians of APSAT. J.Epidemiol.Community Health 1993; 47:64-68. 
Karasek R, Brisson C, Kawakami N, Houtman I, Bongers P, Amick B. The Job Content Questionnaire (JCQ): an instrument for internationally comparative assessments of psychosocial job characteristics. J.Occup.Health Psychol. 1998; 3:322-355.

Karasek R, Choi B, Ostergren PO, Ferrario M, De SP. Testing two methods to create comparable scale scores between the Job Content Questionnaire (JCQ) and JCQ-like questionnaires in the European JACE Study. Int.J Behav.Med 2007; 14:189-201.

Kivimaki M, Honkonen T, Wahlbeck K, Elovainio M, Pentti J, Klaukka T, Virtanen M, Vahtera J. Organisational downsizing and increased use of psychotropic drugs among employees who remain in employment. J Epidemiol Community Health 2007; 61:154-158.

Laaksonen M, Lallukka T, Lahelma E, Partonen T. Working conditions and psychotropic medication: a prospective cohort study. Soc.Psychiatry Psychiatr.Epidemiol. 2012; 47:663670.

Lallukka T, Arber S, Laaksonen M, Lahelma E, Partonen T, Rahkonen O. Work-family conflicts and subsequent sleep medication among women and men: a longitudinal registry linkage study. Soc.Sci.Med 2013; 79:66-75.

Lallukka T, Haukka J, Partonen T, Rahkonen O, Lahelma E. Workplace bullying and subsequent psychotropic medication: a cohort study with register linkages. BMJ Open. 2012; 2 .

Lavigne E, Bourbonnais R. Psychosocial work environment, interpersonal violence at work and psychotropic drug use among correctional officers. Int.J Law Psychiatry 2010; 33:122129.

Madsen IE, Burr H, Diderichsen F, Pejtersen JH, Borritz M, Bjorner JB, Rugulies R. Workrelated violence and incident use of psychotropics. Am.J.Epidemiol. 2011; 174:1354-1362.

Madsen IE, Diderichsen F, Burr H, Rugulies R. Person-related work and incident use of antidepressants: relations and mediating factors from the Danish work environment cohort study. Scand J Work Environ.Health 2010; 36:435-444.

Madsen IE, Hanson LL, Rugulies R, Theorell T, Burr H, Diderichsen F, Westerlund H. Does good leadership buffer effects of high emotional demands at work on risk of antidepressant treatment? A prospective study from two Nordic countries. Soc.Psychiatry Psychiatr.Epidemiol. 2014; 49:1209-1218.

Magnusson Hanson LL, Leineweber C, Chungkham HS, Westerlund H. Work-home interference and its prospective relation to major depression and treatment with antidepressants. Scand J Work Environ Health 2014; 40:66-73.

Magnusson Hanson LL, Madsen IE, Westerlund H, Theorell T, Burr H, Rugulies R. Antidepressant use and associations with psychosocial work characteristics. A comparative study of Swedish and Danish gainfully employed. J Affect.Disord. 2013; 149:38-45.

Malard L, Chastang J-F, Niedhammer I. Changes in psychosocial work factors in the French working population between 2006 and 2010. Int Arch Occup Environ Health 2014; (in press).

Marchand A, Blanc ME. [Chronic psychotropic drugs use in the Canadian labor force: what are the contributions of occupation and work organization conditions?]. Rev.Epidemiol.Sante Publique 2010; 58:89-99.

Metsa-Simola N, Martikainen P. Divorce and changes in the prevalence of psychotropic medication use: a register-based longitudinal study among middle-aged Finns. Soc.Sci.Med $2013 ; 94: 71-80$. 
Moisan J, Bourbonnais R, Brisson C, Gaudet M, Vézina M, Vinet A, Grégoire JP. Job strain and psychotropic drug use among white-collar workers. Work \& Stress 1999; 13:289-298.

Murcia M, Chastang JF, Niedhammer I. Psychosocial work factors, major depressive and generalised anxiety disorders: Results from the French national SIP study. J Affect.Disord. 2013; 146:319-327.

Murcia M, Chastang JF, Niedhammer I. Educational inequalities in major depressive and generalized anxiety disorders: results from the French national SIP study. Soc.Psychiatry Psychiatr.Epidemiol. 2015.

Niedhammer I, Chastang JF. Psychosocial work factors and first depressive episode: retrospective results from the French national SIP survey. Int Arch Occup Environ Health 2014.

Niedhammer I, David S, Degioanni S, Drummond A, Philip P. Workplace bullying and psychotropic drug use: the mediating role of physical and mental health status. Ann.Occup Hyg. 2011; 55:152-163.

Niedhammer I, Lert F, Marne MJ. Psychotropic drug use and shift work among French nurses (1980-1990). Psychol.Med. 1995; 25:329-338.

Niedhammer I, Saurel-Cubizolles MJ, Piciotti M, Bonenfant S. How is sex considered in recent epidemiological publications on occupational risks? Occup Environ Med 2000; 57:521527.

Nylen L, Melin B, Laflamme L. Interference between work and outside-work demands relative to health: unwinding possibilities among full-time and part-time employees. Int.J.Behav.Med 2007; 14:229-236.

Palmer KT, D'Angelo S, Harris EC, Linaker C, Coggon D. The role of mental health problems and common psychotropic drug treatments in accidental injury at work: a casecontrol study. Occup.Environ.Med 2014; 71:308-312.

Paulose-Ram R, Safran MA, Jonas BS, Gu Q, Orwig D. Trends in psychotropic medication use among U.S. adults. Pharmacoepidemiol.Drug Saf 2007; 16:560-570.

Pelfrene E, Vlerick P, Kittel F, Mak RP, Kornitzer M, De Backer G. Psychosocial work environment and psychological well-being: assessment of the buffering effects in the job demand-control (-support) model in BELSTRESS. Stress and Health 2002; 18:43-56.

Pelfrene E, Vlerick P, Moreau M, Mak RP, Kornitzer M, De Backer G. Use of benzodiazepine drugs and perceived job stress in a cohort of working men and women in Belgium. Results from the BELSTRESS-study. Soc.Sci.Med 2004; 59:433-442.

Rugulies R, Aust B, Pejtersen JH. Do psychosocial work environment factors measured with scales from the Copenhagen Psychosocial Questionnaire predict register-based sickness absence of 3 weeks or more in Denmark? Scand.J.Public Health 2010a; 38:42-50.

Rugulies R, Thielen K, Nygaard E, Diderichsen F. Job insecurity and the use of antidepressant medication among Danish employees with and without a history of prolonged unemployment: a 3.5-year follow-up study. J Epidemiol.Community Health 2010b; 64:75-81.

Siegrist J. Adverse health effects of high-effort/low-reward conditions. J.Occup.Health Psychol. 1996; 1:27-41.

Sinokki M, Ahola K, Hinkka K, Sallinen M, Harma M, Puukka P, Klaukka T, Lonnqvist J, Virtanen M. The association of social support at work and in private life with sleeping problems in the Finnish health 2000 study. J Occup Environ.Med 2010; 52:54-61. 
Sinokki M, Hinkka K, Ahola K, Koskinen S, Kivimaki M, Honkonen T, Puukka P, Klaukka T, Lonnqvist J, Virtanen M. The association of social support at work and in private life with mental health and antidepressant use: the Health 2000 Study. J Affect.Disord. 2009; 115:3645 .

Storr CL, Trinkoff AM, Anthony JC. Job strain and non-medical drug use. Drug Alcohol Depend. 1999; 55:45-51.

Thielen K, Nygaard E, Rugulies R, Diderichsen F. Job stress and the use of antidepressant medicine: a 3.5-year follow-up study among Danish employees. Occup Environ Med 2011; 68:205-210.

Traweger C, Kinzl JF, Traweger-Ravanelli B, Fiala M. Psychosocial factors at the workplace-do they affect substance use? Evidence from the Tyrolean workplace study. Pharmacoepidemiol.Drug Saf 2004; 13:399-403.

Vartia ML. Consequences of workplace bullying with respect to the well-being of its targets and the observers of bullying. Scand.J Work Environ Health 2001; 27:63-69.

Verger P, Aulagnier M, Protopopescu C, Villani P, Gourrheux JC, Bouvenot G, Paraponaris A. Hypnotic and tranquillizer use among general practitioners in south-eastern France and its relation to occupational characteristics and prescribing habits. Fundam.Clin.Pharmacol. 2004; 18:379-385.

Virtanen M, Honkonen T, Kivimaki M, Ahola K, Vahtera J, Aromaa A, Lonnqvist J. Work stress, mental health and antidepressant medication findings from the Health 2000 Study. J Affect.Disord. 2007; 98:189-197.

Virtanen M, Kivimaki M, Ferrie JE, Elovainio M, Honkonen T, Pentti J, Klaukka T, Vahtera J. Temporary employment and antidepressant medication: a register linkage study. J Psychiatr.Res. 2008; 42:221-229.

Wittchen HU, Muhlig S, Beesdo K. Mental disorders in primary care. Dialogues.Clin.Neurosci. 2003; 5:115-128. 
Table 1

Description of the study sample in 2006 according to psychotropic drug use, covariates and occupational factors for men and women

\begin{tabular}{|c|c|c|c|c|c|c|c|}
\hline & \multicolumn{3}{|c|}{ Women $(\mathrm{N}=3829)$} & \multicolumn{3}{|c|}{$\operatorname{Men}(\mathrm{N}=3713)$} & \multirow[t]{2}{*}{$\mathrm{p}$} \\
\hline & $\mathrm{n}$ & $\%$ & $\% \mathrm{w}$ & $\mathrm{n}$ & $\%$ & $\% \mathrm{w}$ & \\
\hline \multicolumn{8}{|l|}{ Psychotropic drug use } \\
\hline Any psychotropic drug & 938 & 24.50 & 23.30 & 459 & 12.36 & 12.33 & $* * *$ \\
\hline Anxiolytic & 630 & 16.45 & 15.86 & 303 & 8.16 & 8.10 & $* * *$ \\
\hline Antidepressant & 389 & 10.16 & 9.36 & 148 & 3.99 & 3.98 & $* * *$ \\
\hline Hypnotic & 354 & 9.25 & 8.55 & 215 & 5.79 & 5.68 & $* * *$ \\
\hline Age (y) & & & & & & & ns \\
\hline$<30$ & 450 & 11.75 & 16.95 & 465 & 12.52 & 16.95 & \\
\hline $30-39$ & 961 & 25.10 & 25.97 & 972 & 26.18 & 28.30 & \\
\hline $40-49$ & 1258 & 32.85 & 30.23 & 1129 & 30.41 & 29.41 & \\
\hline$\geq 50$ & 1160 & 30.30 & 26.86 & 1147 & 30.89 & 25.34 & \\
\hline Occupation & & & & & & & $* * *$ \\
\hline Managers/professionals & 503 & 13.14 & 12.46 & 635 & 17.12 & 18.28 & \\
\hline Associate professionals/technicians & 1019 & 26.63 & 25.01 & 901 & 24.29 & 24.81 & \\
\hline Clerks/service workers & 1890 & 49.39 & 49.80 & 538 & 14.51 & 16.63 & \\
\hline Manual workers & 415 & 10.84 & 12.74 & 1635 & 44.08 & 40.28 & \\
\hline Living alone & 1220 & 31.86 & 24.98 & 937 & 25.24 & 21.55 & $* *$ \\
\hline Dependent child under $3 \mathrm{y}$ & 308 & 8.04 & 10.09 & 385 & 10.37 & 12.77 & $* *$ \\
\hline Low social support outside work & 1334 & 34.84 & 32.91 & 1035 & 27.88 & 27.75 & $* * *$ \\
\hline Life event during childhood & 1953 & 51.01 & 51.21 & 1723 & 46.40 & 46.02 & $* * *$ \\
\hline Life event within the last four years & 477 & 12.46 & 11.84 & 357 & 9.62 & 9.04 & $* * *$ \\
\hline \multicolumn{8}{|l|}{ Psychosocial working conditions } \\
\hline High psychological demands & 1442 & 37.66 & 36.88 & 1575 & 42.42 & 43.29 & $* * *$ \\
\hline Low decision latitude & 1292 & 33.74 & 34.11 & 1257 & 33.85 & 34.50 & ns \\
\hline Low social support & 860 & 22.46 & 22.62 & 905 & 24.37 & 24.89 & $*$ \\
\hline Low reward & 1253 & 32.72 & 32.79 & 1162 & 31.30 & 31.98 & ns \\
\hline Hiding emotions & 1893 & 49.44 & 48.94 & 1267 & 34.12 & 36.04 & $* * *$ \\
\hline Role conflict & 1801 & 47.04 & 46.36 & 1664 & 44.82 & 45.67 & ns \\
\hline Ethical conflict & 1156 & 30.19 & 29.72 & 1347 & 36.28 & 36.41 & $* * *$ \\
\hline Tensions with the public & 1771 & 46.25 & 46.23 & 1506 & 40.56 & 42.17 & $* *$ \\
\hline Job insecurity & 815 & 21.28 & 21.42 & 855 & 23.03 & 23.82 & $*$ \\
\hline Work-life imbalance & 1141 & 29.80 & 30.26 & 1133 & 30.51 & 32.39 & ns \\
\hline \multicolumn{8}{|l|}{ Working schedule } \\
\hline Long working hours & 828 & 21.62 & 21.24 & 1547 & 41.66 & 42.79 & $* * *$ \\
\hline Night work & 378 & 9.87 & 9.99 & 904 & 24.35 & 24.62 & $* * *$ \\
\hline Shift work & 539 & 14.08 & 14.67 & 646 & 17.40 & 17.40 & $* *$ \\
\hline Unpredictable working hours & 879 & 22.96 & 23.14 & 1262 & 33.99 & 35.11 & $* * *$ \\
\hline \multicolumn{8}{|l|}{ Physical working conditions } \\
\hline Biomechanical exposure & 1245 & 32.52 & 33.90 & 1638 & 44.12 & 42.92 & $* * *$ \\
\hline Physical exposure & 1015 & 26.51 & 27.14 & 1899 & 51.14 & 48.78 & $* * *$ \\
\hline Chemical exposure & 933 & 24.37 & 25.45 & 1666 & 44.87 & 42.75 & $* * *$ \\
\hline
\end{tabular}


Table 2

Cross-sectional associations between occupational factors and psychotropic drug use, adjusted for covariates in 2006: results of weighted Poisson regression analysis

\begin{tabular}{|c|c|c|c|c|c|c|}
\hline & \multicolumn{6}{|c|}{ Men and women $(\mathrm{N}=7531)$} \\
\hline & $\mathrm{RR}^{\dagger}$ & $95 \% \mathrm{CI}$ & $\mathrm{p}$ & $\mathrm{RR}^{t}$ & $95 \% \mathrm{CI}$ & $\mathrm{p}$ \\
\hline \multicolumn{7}{|c|}{ Psychosocial working conditions } \\
\hline High psychological demands & 1.41 & {$[1.26 ; 1.57]$} & $* * *$ & 1.28 & {$[1.14 ; 1.45]$} & $* * *$ \\
\hline Low decision latitude & 1.20 & {$[1.07 ; 1.34]$} & $* * *$ & 1.06 & {$[0.94 ; 1.20]$} & ns \\
\hline Low social support & 1.44 & {$[1.28 ; 1.62]$} & $* * *$ & 1.31 & {$[1.16 ; 1.48]$} & $* * *$ \\
\hline Low reward & 1.29 & {$[1.15 ; 1.44]$} & $* * *$ & 1.11 & {$[0.99 ; 1.25]$} & ns \\
\hline Hiding emotions & 1.37 & {$[1.23 ; 1.53]$} & $* * *$ & 1.28 & {$[1.14 ; 1.43]$} & $* * *$ \\
\hline Role conflict & 1.15 & {$[1.03 ; 1.29]$} & $* *$ & 0.96 & {$[0.85 ; 1.09]$} & ns \\
\hline Ethical conflict & 1.16 & {$[1.04 ; 1.30]$} & $* *$ & 1.01 & {$[0.90 ; 1.13]$} & ns \\
\hline Tensions with the public & 1.13 & {$[1.01 ; 1.26]$} & $*$ & 0.99 & {$[0.88 ; 1.11]$} & $\mathrm{ns}$ \\
\hline Job insecurity & 1.31 & {$[1.16 ; 1.48]$} & $* * *$ & 1.17 & {$[1.04 ; 1.33]$} & $*$ \\
\hline Work-life imbalance & 1.12 & {$[0.99 ; 1.26]$} & $\mathrm{ns}$ & 0.99 & {$[0.88 ; 1.12]$} & ns \\
\hline \multicolumn{7}{|l|}{ Working schedule } \\
\hline Long working hours & 0.88 & {$[0.77 ; 1.00]$} & $*$ & 0.80 & {$[0.70 ; 0.92]$} & $* *$ \\
\hline Night work & 0.91 & {$[0.78 ; 1.08]$} & ns & 0.92 & {$[0.77 ; 1.09]$} & ns \\
\hline Shift work & 0.99 & {$[0.85 ; 1.15]$} & ns & 0.93 & {$[0.80 ; 1.09]$} & ns \\
\hline Unpredictable working hours & 1.07 & {$[0.95 ; 1.21]$} & ns & 1.07 & {$[0.93 ; 1.21]$} & ns \\
\hline \multicolumn{7}{|l|}{ Physical working conditions } \\
\hline Biomechanical exposure & 1.13 & {$[1.00 ; 1.27]$} & $*$ & 1.12 & {$[0.98 ; 1.28]$} & ns \\
\hline Physical exposure & 0.99 & {$[0.87 ; 1.12]$} & ns & 0.87 & {$[0.76 ; 1.00]$} & ns \\
\hline Chemical exposure & 1.01 & {$[0.89 ; 1.14]$} & $\mathrm{ns}$ & 0.97 & {$[0.85 ; 1.11]$} & ns \\
\hline
\end{tabular}

RR adjusted for gender, age, occupation, marital status, dependent child, social support outside work and life events

${ }^{\dagger}$ Occupational factors studied separately ${ }^{\ddagger}$ All occupational factors studied simultaneously

Bold: RR significant at $5 \%$

Wald test: ***: $\mathrm{p} \leq 0.001,{ }^{* *}: \mathrm{p} \leq 0.01,{ }^{*}: \mathrm{p} \leq 0.05$, ns: non-significant 
Table 3

Prospective associations between occupational factors in 2006 and psychotropic drug use in 2010, adjusted for covariates: results of weighted Poisson regression analysis

\begin{tabular}{|c|c|c|c|c|c|c|}
\hline & \multicolumn{6}{|c|}{ Men and women $(\mathrm{N}=4208)$} \\
\hline & $\mathrm{RR}^{\dagger}$ & $95 \% \mathrm{CI}$ & $\mathrm{p}$ & $\mathrm{RR}^{\dagger}$ & $95 \% \mathrm{CI}$ & $\mathrm{p}$ \\
\hline \multicolumn{7}{|l|}{ Psychosocial working conditions } \\
\hline High psychological demands & 1.37 & {$[1.11 ; 1.68]$} & $* *$ & 1.24 & {$[0.98 ; 1.57]$} & ns \\
\hline Low decision latitude & 1.28 & {$[1.04 ; 1.58]$} & $*$ & 1.21 & {$[0.97 ; 1.51]$} & ns \\
\hline Low social support & 1.20 & {$[0.95 ; 1.50]$} & ns & 1.06 & {$[0.83 ; 1.36]$} & ns \\
\hline Low reward & 1.17 & {$[0.94 ; 1.46]$} & ns & 1.01 & {$[0.80 ; 1.28]$} & ns \\
\hline Hiding emotions & 1.58 & {$[1.28 ; 1.96]$} & $* * *$ & 1.53 & {$[1.23 ; 1.89]$} & $* * *$ \\
\hline Role conflict & 1.13 & {$[0.92 ; 1.38]$} & ns & 0.98 & {$[0.78 ; 1.24]$} & ns \\
\hline Ethical conflict & 1.05 & {$[0.84 ; 1.30]$} & ns & 0.88 & {$[0.69 ; 1.11]$} & ns \\
\hline Tensions with the public & 1.17 & {$[0.95 ; 1.44]$} & ns & 1.04 & {$[0.84 ; 1.28]$} & ns \\
\hline Job insecurity & 1.19 & {$[0.94 ; 1.51]$} & $\mathrm{ns}$ & 1.09 & {$[0.86 ; 1.38]$} & $\mathrm{ns}$ \\
\hline Work-life imbalance & 1.20 & {$[0.96 ; 1.51]$} & $\mathrm{ns}$ & 1.12 & {$[0.88 ; 1.42]$} & ns \\
\hline \multicolumn{7}{|l|}{ Working schedule } \\
\hline Long working hours & 0.89 & {$[0.70 ; 1.12]$} & ns & 0.80 & {$[0.61 ; 1.04]$} & ns \\
\hline Night work & 1.02 & {$[0.76 ; 1.36]$} & $\mathrm{ns}$ & 0.98 & {$[0.72 ; 1.34]$} & $\mathrm{ns}$ \\
\hline Shift work & 1.05 & {$[0.80 ; 1.39]$} & ns & 0.95 & {$[0.71 ; 1.29]$} & ns \\
\hline Unpredictable working hours & 0.98 & {$[0.78 ; 1.23]$} & ns & 0.93 & {$[0.72 ; 1.19]$} & ns \\
\hline \multicolumn{7}{|l|}{ Physical working conditions } \\
\hline Biomechanical exposure & 1.09 & {$[0.88 ; 1.37]$} & $\mathrm{ns}$ & 0.90 & {$[0.71 ; 1.14]$} & $\mathrm{ns}$ \\
\hline Physical exposure & 1.39 & {$[1.13 ; 1.73]$} & $* *$ & 1.30 & {$[1.02 ; 1.64]$} & $*$ \\
\hline Chemical exposure & 1.14 & {$[0.90 ; 1.43]$} & $\mathrm{ns}$ & 1.09 & {$[0.85 ; 1.40]$} & ns \\
\hline
\end{tabular}


Table 4

Prospective associations between repeated exposure to occupational factors in 2006 and 2010 and psychotropic drug use in 2010, adjusted for covariates: results of weighted Poisson regression analysis

\begin{tabular}{|c|c|c|c|c|}
\hline & \multicolumn{4}{|c|}{ Men and women $(\mathrm{N}=4208)$} \\
\hline & $\mathrm{RR}_{1} / \mathrm{RR}_{2} / \mathrm{RR}_{3}^{\dagger}$ & $p$ & $\mathrm{RR}_{1} / \mathrm{RR}_{2} / \mathrm{RR}_{3}{ }^{*}$ & $p$ \\
\hline \multicolumn{5}{|c|}{ Psychosocial working conditions } \\
\hline High psychological demands & $1.01 / 1.76 / 2.04$ & $* * *$ & 0.93/1.38/1.66 & $* * *$ \\
\hline Low decision latitude & $1.10 / \mathbf{1 . 5 9} / 1.84$ & $* * *$ & 1.08/1.36/1.60 & $* *$ \\
\hline Low social support & $1.19 / 1.26 / 1.36$ & ns & $1.08 .1 .05 / 1.01$ & ns \\
\hline Low reward & $1.10 / \mathbf{1 . 6 2} / \mathbf{1 . 6 0}$ & $* * *$ & $0.95 / 1.25 / 1.17$ & ns \\
\hline Hiding emotions & $1.57 / 2.00 / 2.30$ & $* * *$ & 1.53/1.79/2.02 & $* * *$ \\
\hline Role conflict & $1.26 / 1.23 / 1.22$ & ns & $1.14 / 0.96 / 0.78$ & ns \\
\hline Ethical conflict & $0.84 / \mathbf{1 . 3 4} / \mathbf{1 . 3 5}$ & $*$ & $0.73 / 1.04 / 1.02$ & ns \\
\hline Tensions with the public & $0.96 / 0.98 / 1.25$ & ns & $0.92 / 0.74 / 0.86$ & ns \\
\hline Job insecurity & $1.09 / \mathbf{1 . 5 5} / \mathbf{1 . 5 1}$ & $* *$ & $0.99 / 1.30 / 1.14$ & ns \\
\hline Work-life imbalance & 1.08/1.43/1.53 & $* *$ & $0.98 / 1.16 / 1.24$ & ns \\
\hline \multicolumn{5}{|l|}{ Working schedule } \\
\hline Long working hours & $1.07 / 1.05 / 0.79$ & ns & $1.00 / 0.88 / 0.59$ & $*$ \\
\hline Night work & $1.17 / 1.25 / 0.97$ & ns & $1.07 / 1.01 .0 .86$ & ns \\
\hline Shift work & $1.00 / \mathbf{1 . 5 4} / 1.17$ & ns & $0.83 / 1.30 / 0.93$ & ns \\
\hline Unpredictable working hours & $0.92 / 1.32 / 1.13$ & ns & $0.84 / 1.22 / 1.00$ & ns \\
\hline \multicolumn{5}{|l|}{ Physical working conditions } \\
\hline Biomechanical exposure & $0.89 / \mathbf{1 . 4 8} / \mathbf{1 . 3 8}$ & $* *$ & $0.74 / 1.30 / 1.01$ & ns \\
\hline Physical exposure & 1.32/1.38/1.61 & $* *$ & $1.34 / 1.03 / 1.28$ & ns \\
\hline Chemical exposure & $1.25 / 1.28 / 1.18$ & ns & $1.26 / 1.06 / 1.02$ & ns \\
\hline
\end{tabular}

RR adjusted for gender, age, occupation, marital status, dependent child, social support outside work and life events ${ }^{\dagger}$ Occupational factors studied separately ${ }^{\ddagger}$ All occupational factors studied simultaneously

Reference group: non-exposed in 2006 and 2010, $\mathrm{RR}_{1}$ : exposed in 2006 and non-exposed in 2010, $\mathrm{RR}_{2}$ : non-exposed in 2006 and exposed in 2010, $\mathrm{RR}_{3}$ : exposed in 2006 and 2010

Bold: RR significant at $5 \%$

Global Wald test: ${ }^{* *}: \mathrm{p} \leq 0.001, * *: \mathrm{p} \leq 0.01, *: \mathrm{p} \leq 0.05$, ns: non-significant 